\title{
Tomaž PIPAN \\ Branje delte Biserne reke s stališča Alda Rossija
}

Ta članek obravnava Rossijevo metodologijo razumevanja mest na primeru Šenzena, ki se je iz vasi v manj kot 15 letih razvil v sodobno mesto z več kot štirimi milijoni prebivalcev. Avtor članka upošteva temeljne instrumente teorije, ki jo je Rossi predstavil v svoji knjigi The Architecture of the City (L'architettura della città), ter jih sistematično uporabi in preizkusi na primeru obravnavanega mesta. Tako naredi kritično oceno metodologije in predlaga možne spremembe.

KLUČnE BESEDE: urbanizem, Šenzen, Kitajska, delta Biserne reke, Aldo Rossi.

\section{Uvod}

Zmožnost branja in razumevanja mesta ter urbanih procesov se razume kot eno glavnih nujnosti vsakega urbanista. Vendar množica znanstvenih besedil in številne teorije, ki so nastali na podlagi tega prepričanja, ne potrjujejo, da je tako razumevanje enoznačno ali pa sploh mogoče. Je ta težava povezana s teoretičnim diskurzom ali z naravo mesta? Morda pa je povezana s subjektivnostjo in različnimi načini, s katerimi ljudje zaznavajo mesto in ga razumejo. Naj bo razlog tak ali drugačen, dejstvo, da je mestu doslej vedno uspelo prerasti teorije o sebi, ostaja. Vsaj za zdaj. S tega stališča lahko domnevano, da velja enako tudi za razumevanje mesta, kakršno predlaga Aldo Rossi v The Architecture of the City. Pričujoče besedilo bo soočilo Rossijevo teorijo z novim mestom, ki je vzniknilo na Daljnem vzhodu, postkomunističnim in skrajno kapitalističnim mestom Šenzen.

Razmere in razlogi za nastanek Šenzena so zelo svojevrstni in predvsem različni od razmer v mestih, ki jih je obravnaval Rossi. Ena izmed temeljnih razlik je časovno obdobje, v katerem se je Šenzen razvil iz vasi v razraščeno metropolo. To, za kar so evropska mesta potrebovala več stoletij, je Šenzen dosegel v dveh desetletjih. Kaj se zgodi, ko mesto nastane tako rekoč v hipu, v delčku sekunde? Ali so pravila razumevanja take entitete še vedno v skladu s pravili, ki jih je postavil Rossi?
This article confronts the Rossi's methodology of reading the city with Shenzhen - Chinese contemporary city that developed from a village into a city of 4 million inhabitants in less than 15 years. The article identifies the core instruments of Rossi's theory as presented in his book Architecture of the City and systematically redeploys and tests them on the city in question. Through this a critical evaluation of the methodology is made, furthermore possible modifications are suggested.

KEY WORDs: urbanism, Shenzhen, China, Pearl River Delta, Aldo Rossi.

\section{Uvodne domneve in predmet preučevanja}

Najprej moramo opredeliti glavni problem na katerega se bomo osredotočili in ga kasneje soočili $\mathrm{z}$ Rossijevim teoretičnim pristopom branja mesta. V besedilu se bomo posvetili zgodnji fazi v razvoju Šenzena. Značilna ni samo zanj, ampak za celotno območje delte Biserne reke (DBR). Izhaja iz domneve, da se urbano tkivo $v$ tej fazi sestoji predvsem iz stanovanjske in industrijske gradnje. Čeprav obstajajo tudi terciarni programi, na primer osnovne storitve in nekatere vladne ustanove, jih je premalo, da bi ustrezno »motivirali« in »aktiviriali« urbano tkivo pričujočih razsežnosti. Domneva je zelo drzna zlasti zato, ker so podatki o zgodnjem razvoju v najboljšem primeru skopi. Velika somestja s pretežno industrijskim in stanovanjskim programom so še vedno glavna značilnos severnega dela delte Biserne reke, saj se je urbanizacija tega območja začela pozneje, takrat, ko je Šenzen že prešel v pozno fazo. Za pozno fazo je značilno, da terciarni program prežema urbano tkivo in potiska industrijo na cenejša območja, kot omenjeno, na sever.

Misel o zgodnji fazi podpira tudi dejstvo, da zgodovina $\mathrm{v}$ teh novih konurbacijah nima velike vloge in je ponavadi prirejena trenutnim razvojnim težnjam in potrebam. Za primer: Univerza v Šenzenu je začela prvo generacijo študentov vpisovati v dodiplomski študij leta 1995, ko je program potrdilo kitajsko 
ministrstvo za šolstvo. Univerza navaja, da je bila ustanovljena leta 1983, vendar obstaja 12-letna vrzel brez kakršnihkoli dokumentov. Po letu 1995 je njena "zgodovina" bogata, saj se nanjo vsako leto vpiše veliko študentov. Na univerzi so na to dejstvo zelo ponosni in ga obširno razlagajo.

Razlog, da se članek posveča Šenzenu, in ne drugim delom delte Biserne reke, je prav tako zgodovinski. Čeprav so se razmere v njem izboljšale, je to edino mesto v somestju delte Biserne reke, katerega "zgodovina« je za zadnjih 25 let vsaj delno zapisana.

Analiza se bo posvetila dvema zelo značilnima ur banima artefaktoma ${ }^{[1]} \mathrm{v}$ urbanem tkivu Šenzena, in sicer zgodovinsko nastali urbani vasi in »kapitalistično« načrtovanem novem urbanem tkivu. Razloga za njuno izpostavitev sta dva. Prvi je, da v tkivu Šenzena prevladujeta. In drugi, da se politično, zgodovinsko, geografsko in družbeno ne bi mogla bolj razlikovati. $Z$ analizo obeh skrajnosti si oblikujemo spekter, potreben za analizo različnih primerov.

Najprej si moramo na kratko ogledati zgodovino Šenzena in sile, ki so ga ustvarile. Temu bo sledila razlaga mesta s pomočjo pojmov in orodji, ki jih je razvil Rossi za branje in razumevanje urbane oblike. V članku bomo poskusili oblikovati tudi dodatne instrumente oziroma kritiko Rossijeve teorije.

\section{3. Šenzen}

Pri razlagi zgodbe o Šenzenu se človek hitro znajde v dvomih. Naj mesto upodobi kot uspeh brez primere ali kot katastrofo, ki se lahko zgodi vsak hip? Naj se odloči tako ali drugače, naslednja dejstva ostajajo nespremenjena.

Vse se je začelo leta 1978, ko je vladni uslužbenec po imenu Deng Xiaoping (ki je služil kot de facto voditelj Kitajske), uvedel politiko odprtih vrat, saj so občutljivo komunistično doktrino, ki je temeljila na vase zaprtih in samozadostnih načelih, začele ogrožati vse močnejša globalna ekonomija in kapitalistične sile. Če je hotela Kitajska preživeti, je morala v komunistični ekosistem »subtilno« infiltrirati kapitalistične zamisli in idejo odprtega, svetovnega trga. Politika odprtih vrat je narekovala koncept ene države in dveh sistemov, v katerem je večina Kitajske (ki je bila še vedno komunistična, zaprta in »samozadostna«) žela koristi, ki so jih prinašale posebne ekonomske cone, območja, v katerih so državno načrtovanje ter lastništvo in državno voden razvoj zamenjali z javnozasebnimi družabništvi in s kapitalističnim modelom zahodnega sveta. Te enklave je zgoraj naveden državni uslužbenec označili kot:

"... okno v svet tehnologije, upravljanja, znanja in zunanjih politik. Prek teh con lahko uvažamo

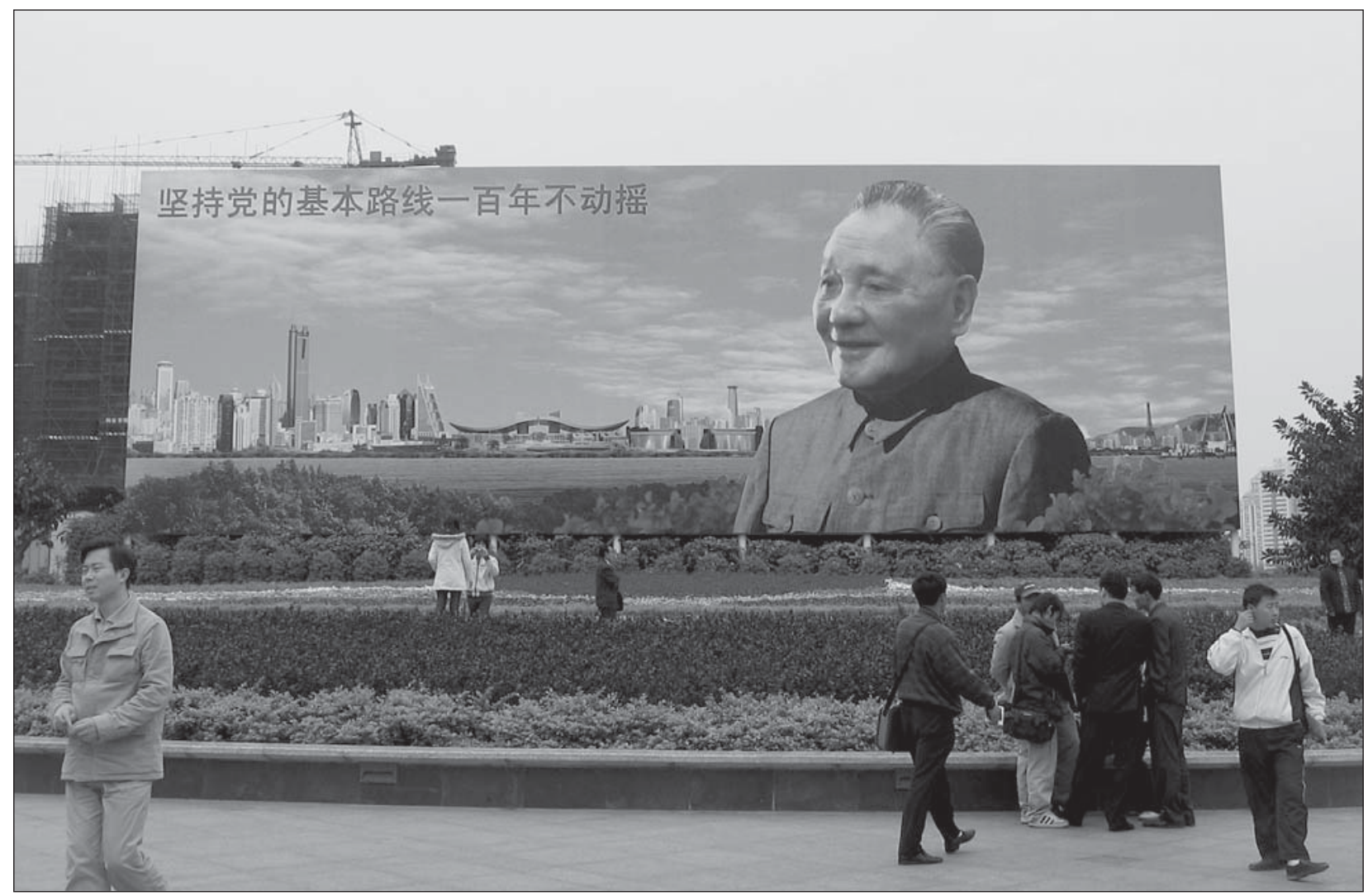

Slika 1: Deng Xiaoping na enem izmed »oglasov« za gradnjo novega Šenzena. (Vir: Chung in dr., 2001) 
tehnologijo, pridobivamo znanje in se učimo vodenja, ki je prav tako oblika znanja. Posebne ekonomske cone bodo postale temelj za odpiranje zunanjemu svetu. Pridobili bomo $v$ gospodarskem smislu ter osebnem usposabljanju in razširili spodbuden vpliv naše države na svet." (Chung in dr., 2001: 115).

Kitajci so z navdušenjem in zavzetostjo in v obsegu, kakršnega so sposobni samo oni, začeli načrtovati in graditi nova vozlišča izmenjav med dvema najbolj nasprotujočima si ideologijama na svetu. Eden izmed poglavitnih vzrokov, da Šenzen spremenijo $\mathrm{v}$ prvo izmed številnih posebnih ekonomskih con, je bila bližina Hongkonga. Leta 1981 so se Kitajci, s pomočjo tujih investitorjev, lotili 600 projektov. $\mathrm{V}$ prihodnjih dveh letih se je 4000 strokovnjakov in 100.000 delavcev posvečalo preoblikovanju preproste ribiške vasi s 25.000 prebivalci. Petnajst let pozneje je bil Šenzen že velikansko mesto s štirimi milijoni prebivalcev (Uehara in dr., 2005).

Posebne ekonomske cone so bile poslovni uspeh. Zaradi velikanskih gospodarskih pritiskov ni bilo časa za strateško načrtovanje. Groba industrijska območja in stanovanjska naselja so gradili glede na potrebe in po predpisanih arhitekturnih receptih. Novo grajeno tkivo se je silovito razmahnilo ter pogoltnilo vse ribiške in poljedelske vasi na območju.

\subsection{Zgodnja faza}

Zgodnja faza drzne in nikjer drugje videne hitrosti zidave je bila aglomerat primarnih in sekundarnih funkcij. Novo urbano tkivo je raslo nenadzorovano. To je povzročilo drobljenje prostora. Industrijska območja so rasla ob stanovanjskih, ta pa ob vaseh, ki so spet mejile na industrijska območja (Slika 3). $\mathrm{V}$ prostorski ureditvi mesta ni bilo nobene logike. Poglavitne gonilne sile gospodarstva in kapitala so imele edinega tekmeca $v$ še bolj zloveščem ohranjanju komunistične dediščine (Slika 2), zlasti v prizadevanjih, da prikažejo in širijo zamisel o napredku in novem razmišljanju s pomočjo vizualne podobo mesta. Ustvarjanje identitete $\mathrm{z}$ arhitekturnimi sredstvi (v čemer so Kitajci zelo spretni) je narekovalo široke bulvarje, prostrane razglede in nečloveške razsežnosti odprtih prostorov. Ob njih so zgradili visoke stanovanjske stolpnice (in edina razlika je, da so jih namesto komunistične partije gradili kapitalistični investitorji) (Slika 4).

Opisana organizacija urbane forme odpira vprašanje, ali je Šenzen sploh mogoče imenovati mesto, saj je bil zasnovan kot generator industrije, kar se na Kitajskem, v državi z dolgo tradicijo razmišljanja $\mathrm{v}$ absolutnih terminih, prevede v kraj za delo - industrijo - in kraj za počitek - stanovanje. Druga

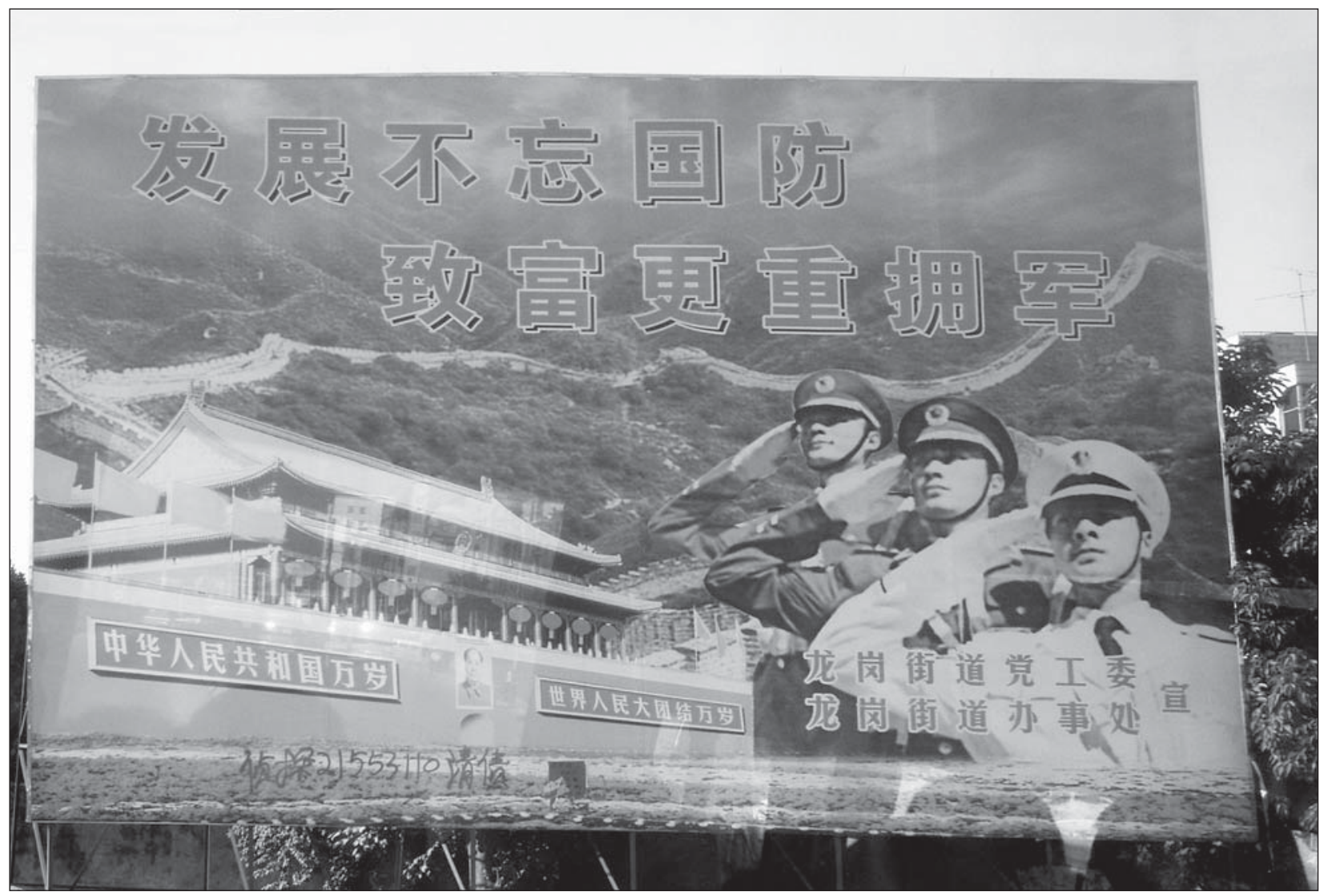

Slika 2: Še vedno navzoča ideološka propaganda. (Foto: Tomaž Pipan) 


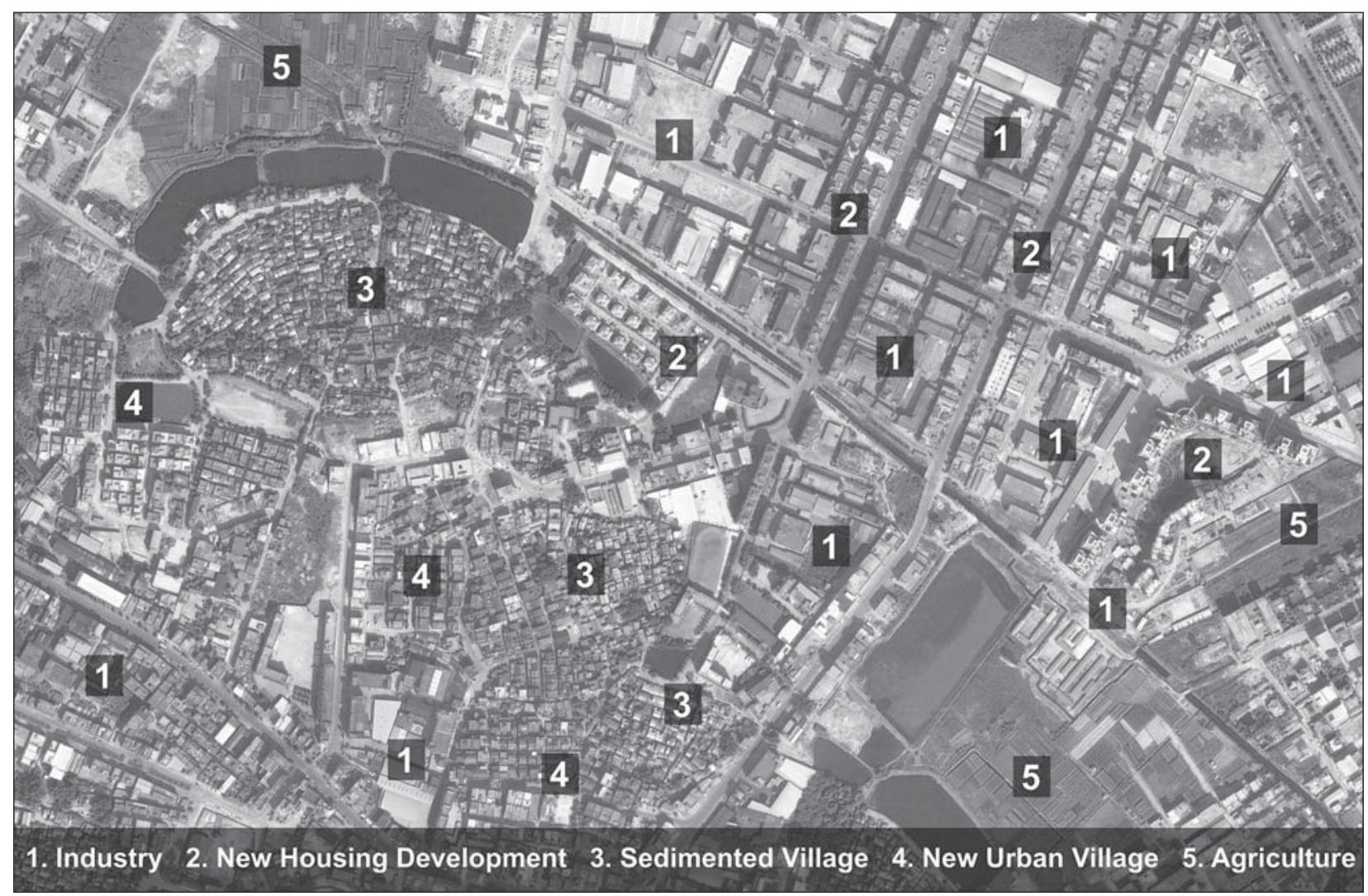

Slika 3: Drobljenje zgrajenega tkiva (zgodnja faza urbanizacije, 60 kilometrov severno od Šenzena). (Vir: internet 1)

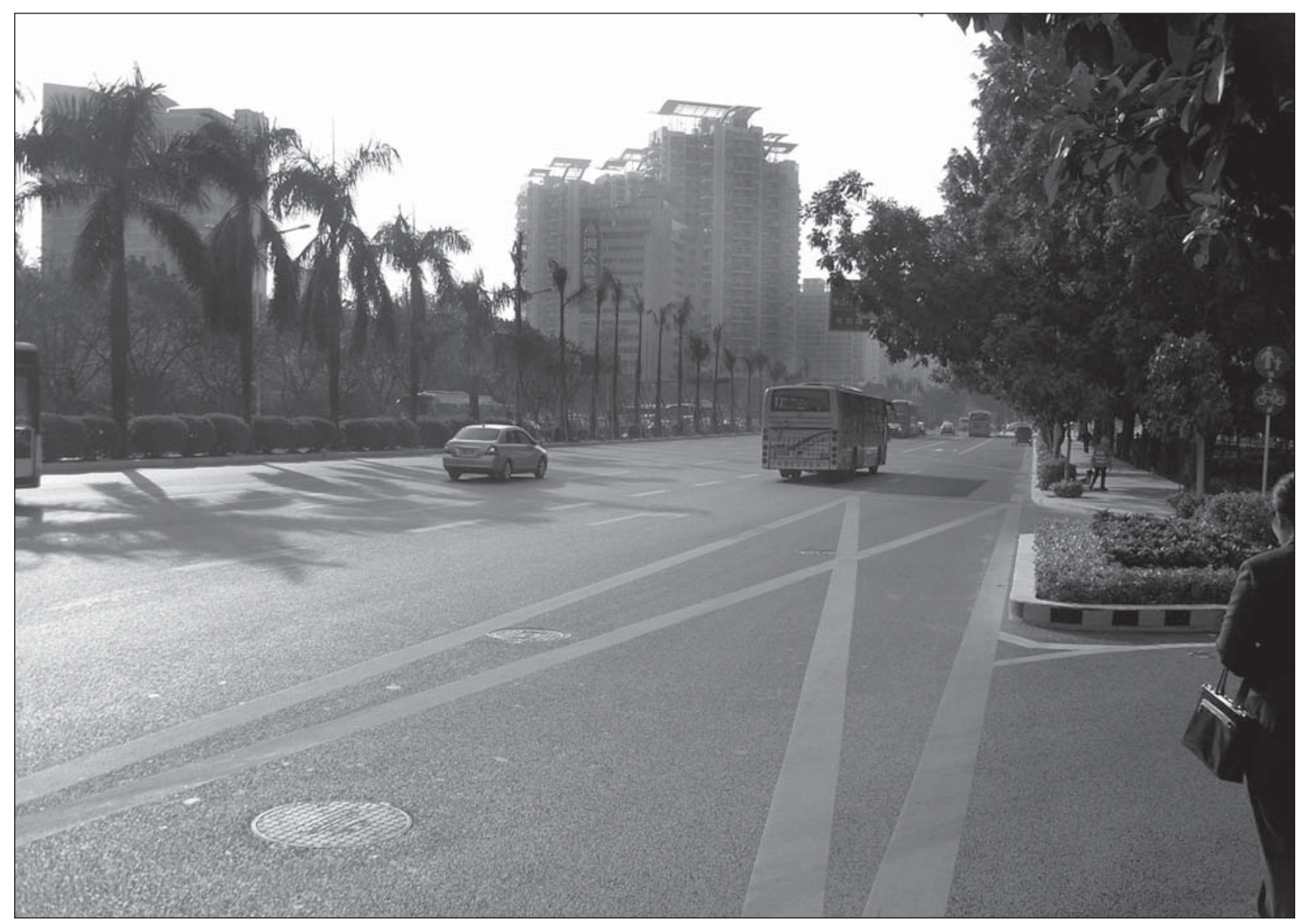

Slika 4: Nova podoba mesta - veliki bulvarji in visoke stanovanjske stolpnice novih kapitalističnih investitorjev. (Foto: Tomaž Pipan) 
težava je v tem, da je večina novih prebivalcev nekdanjih poljedelcev, ki so prišli iz notranjosti Kitajske v upanju, da bodo v Šenzenu našli blaginjo in boljše življenje. S sabo pa so prinesli običaje in slog življenja, primeren za vas. Nova zato ni zgolj fizična podoba mesta, temveč tudi družbena struktura, ki bolj spominja na vaško kot na mestno. Primerna družbena struktura se torej še more izoblikovati.

Iz nenavadne mešanice komunističnih instrumentov propagande in kapitalističnih sil se je rodilo novo mesto sodobne Kitajske. Mesto, zgrajeno na podlagi videza in kapitala, je kraj, v katerem so posamezniki pokopani pod dolgoletno ideologijo in gospodarskimi silami. Če odmislimo sarkazem, se te razmere zrcalijo v odprtem javnem prostoru, ki posamezniku ne nudi kvalitenih bivanjskih pogojev. Zaradi razsežnosti je neuporaben. Postaja prazen in nesocialen. Ljudje potujejo po mestu z motornimi vozili, zlasti $\mathrm{z}$ avtomobili, ki so še ena ikona napredka (Sliki 4 in 5).

\subsection{Poznejša faza}

Po prvemu industrijskem valu in dodatnemu pronicanju kapitalizma v komunistično ideologijo se je začela industrializacija širiti na sever, navzgor po delti Biserne reke. Stanje zgodnje faze še vedno prevladuje $\mathrm{v}$ severnejših območjih delte. To, kar se je zgodilo z vasjo Šenzen in okoliškimi vasmi, se je ponovilo na celotnem območju (Slika 7). Da bi Šenzen prerasel okvirje somestja nekdanjih vaščanov, je bil potreben nov urban katalizator. Katalizator, ki premakne identiteto mesta iz tistega usmerjenega $\mathrm{v}$ proizvodnjo $\mathrm{v}$ tistega usmerjenega $\mathrm{v}$ storitve.

Ko se je Šenzen še bolj povečal, se je pojavil terciarni sektor. Šenzen je s tem postal vsaj delno neodvisen od Hongkonga. Urbano tkivo so začele prežemati entitete, kakršne so univerza, raziskovalna središča in poslovne četrti (Slika 6). Mesto ni bilo več samo industrijski kraj usmerjen $\mathrm{v}$ primarno produkcijo. Ti in njim podobni katalizatorji so omogočili

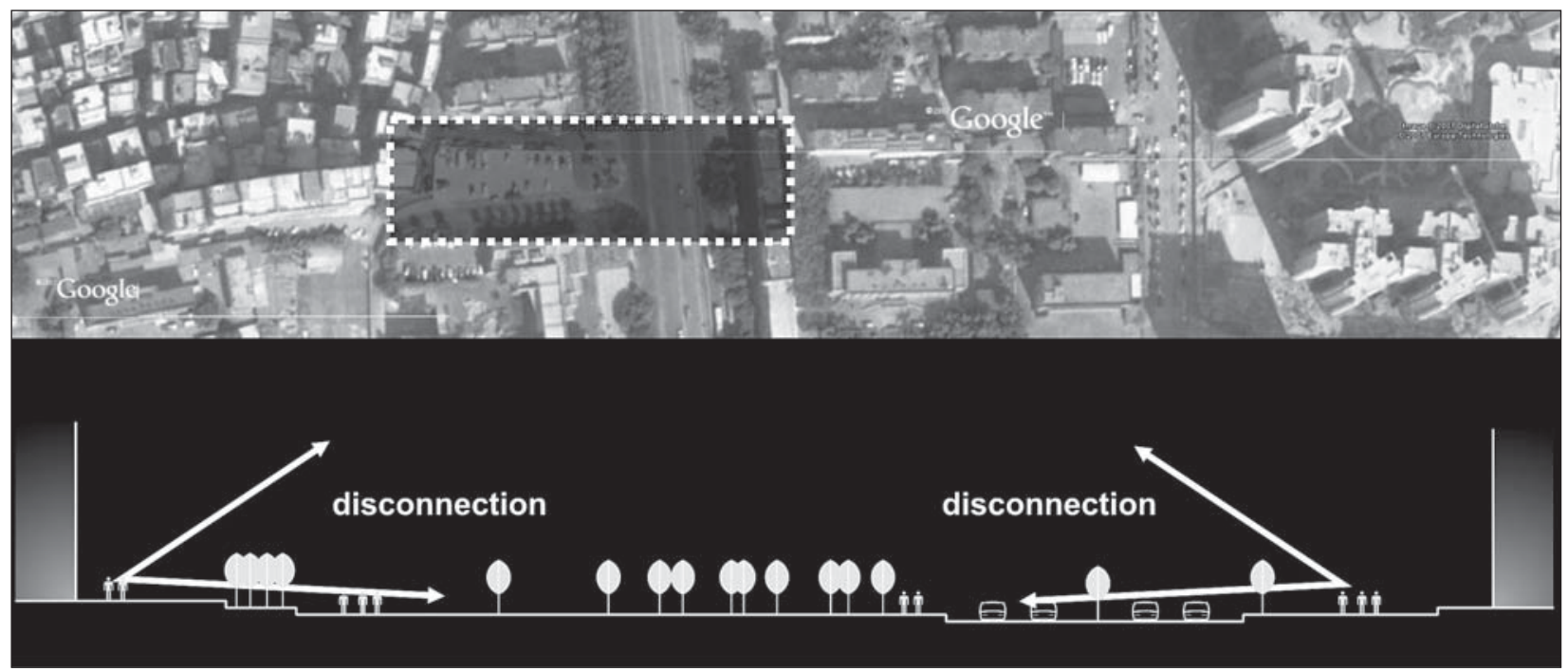

Slika 5: Nečloveške razsežnosti novih načrtovanih pozidav. (Foto: Tomaž Pipan)

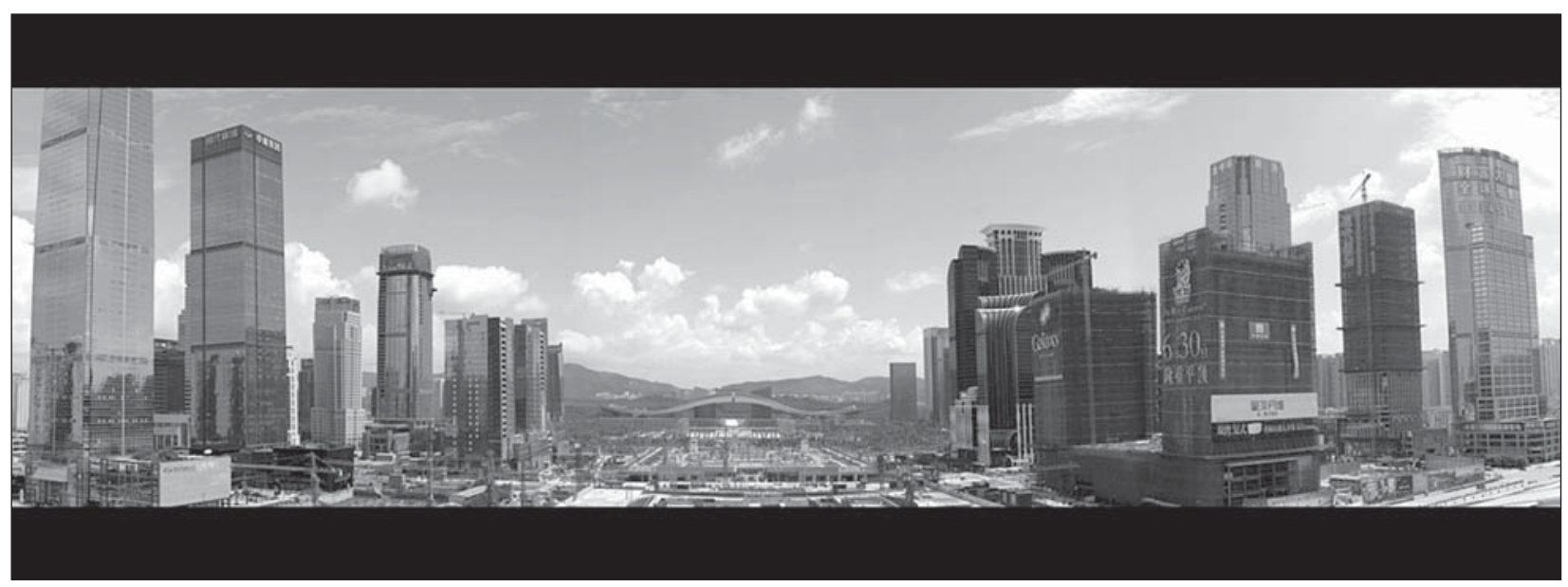

Slika 6: Poslovna četrt v Šenzenu. (Vir: internet 2) 
oblikovanje različnih programskih vozlišč ob pomembnejših ulicah, vendar jih zaradi odsotnosti očitne prostorske ureditve iz načrta ni mogoče razpoznati.

\subsection{Urbana vas}

Urbana vas potrebuje kot zgodovinsko nastala entiteta dodatno pozornost. Ko so nastale posebne ekonomske cone, so kmetom odvzeli obdelovalne površine. Za odškodnino so jim dovolili, da dogradijo svoje vasi in služijo $z$ oddajo na novo pridobljenega prostora. Prvotno vaško tkivo se je hitro preobrazilo in pritlične vaške hiše so zamenjale šestdo devetnadstropne zgradbe, ki so druga od druge

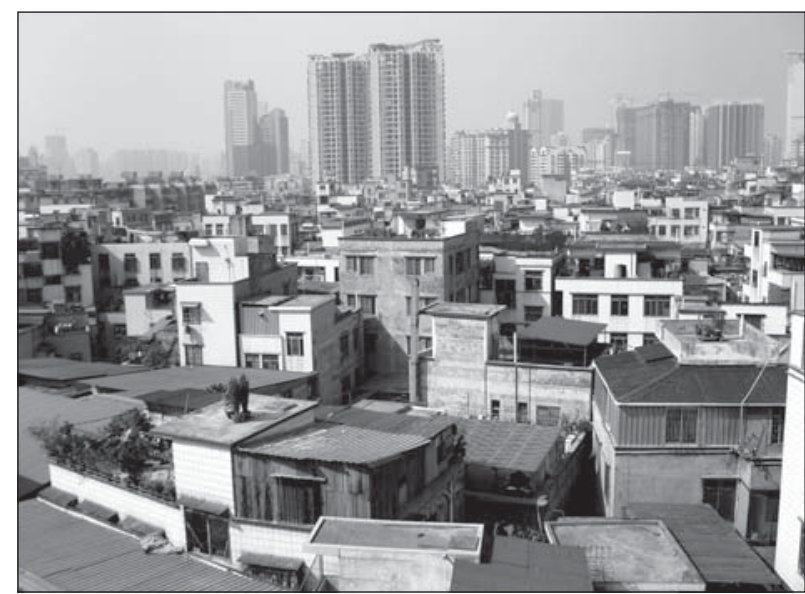

Slika 8: Urbana vas, obkrožena z novimi stanovanjskimi naselji. (Foto: Tomaž Pipan)

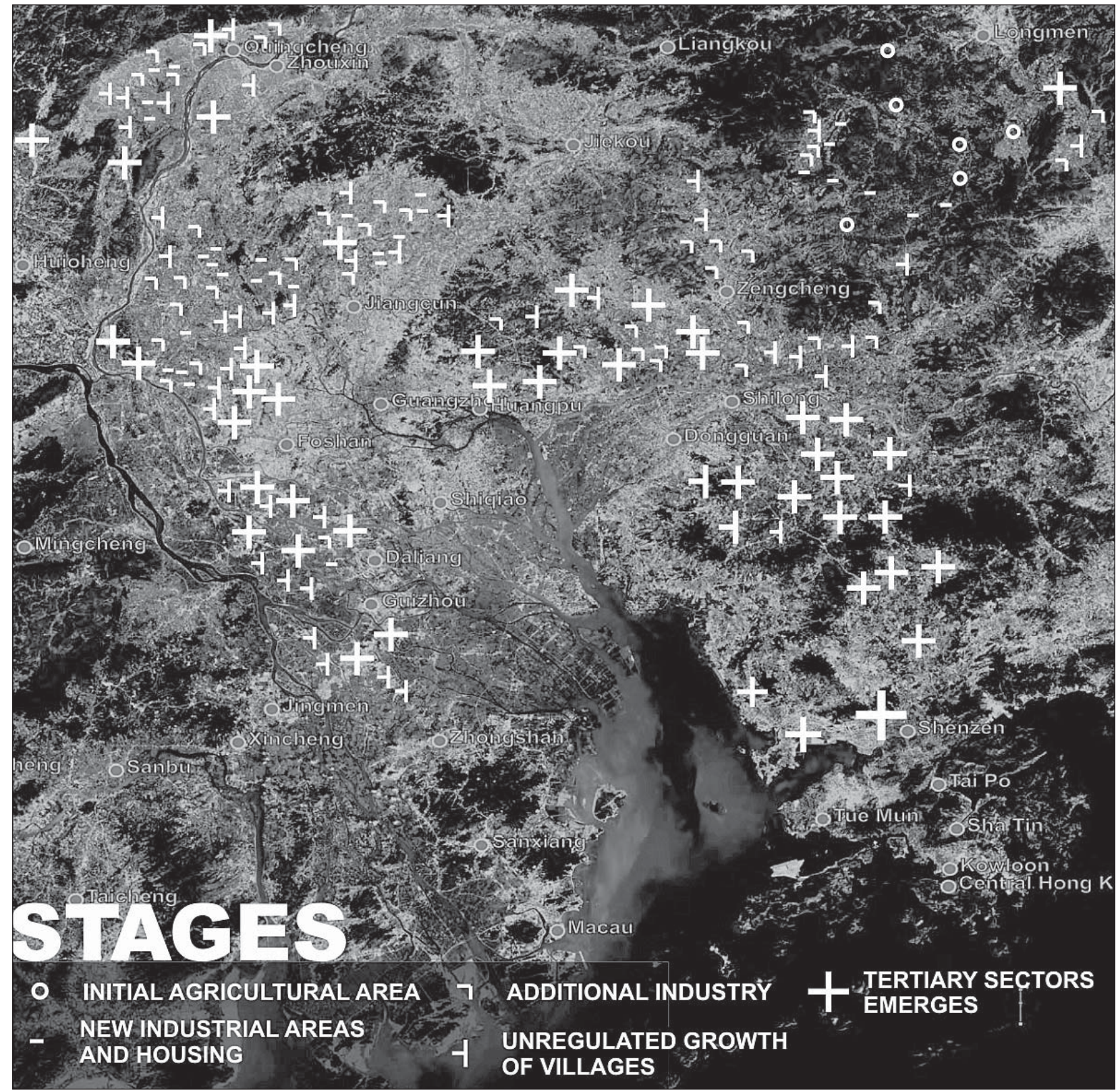

Slika 7: Širitev posebne ekonomske cone, ki ji je sledila selitev industrije iz Šenzena na sever. (Foto: Katya Larina) 
navadno oddaljene le nekaj metrov (Slika 8). Vlada je pri nenadzorovanem urbanizacijskem procesu, ki je kršil vsa gradbena pravila, zamižala na eno oko. Nastal je status quo, ki se je izoblikoval na podlagi odškodnine za izgubljene obdelovalne površine. Ker je bila lastnina zasebna, so imeli vaščani popolno oblast in celo svoje policiste.

Urbana vas je edini zgodovinsko sedimentirani artefakt v vsej urbani pokrajini Šenzena. Te vasi so zrasle iz prvotnih ribiških in kmečkih vasi. Nastale so iz človeških potreb in so imele človeške razsežnosti
(Slika 9). Odprti prostor je medsebojno povezan in prepleten. Uličice vodijo na notranja dvorišča, od tam pa na glavne ulice in trge (Slika 10). Ulična mreža se je ohranila. Nanjo so presadili nove zgradbe. Čeprav so stanovanjske enote precej visoke, razmerje FIZ pa še višje, je človeško merilo vasi pozitivna lastnost $v$ primerjavi z velikopoteznimi »ideološkimi« zazidavami »uradnega« dela Šenzena (Slika 11).

Urbane vasi veljajo za bivališča nižjega srednjega razreda, za prišleke. Predstavljajo najnižji sloj v novorazvijajoči se družbeni strukturi.

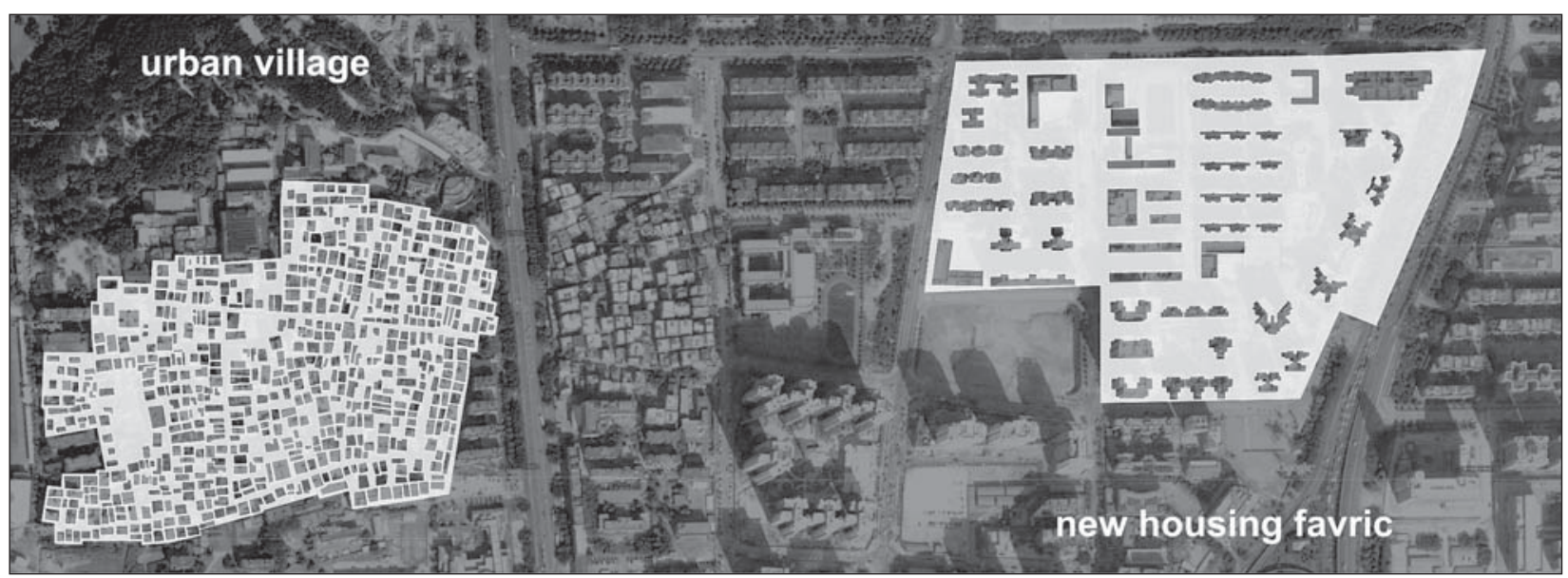

Slika 9: Kakovost odprtega prostora - organizacija v urbani vasi in novo stanovanjsko tkivo. (Foto: Tomaž Pipan)

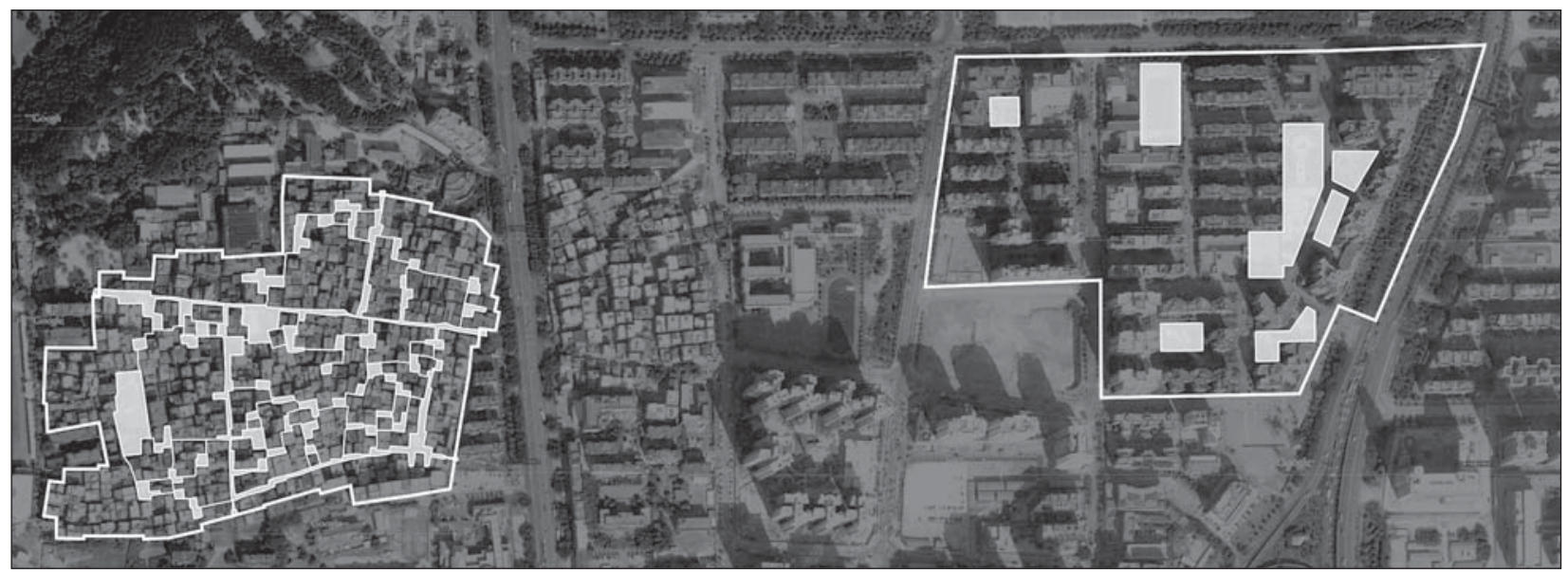

Slika 10: Primerjava povezave javnega prostora v urbani vasi in novem stanovanjskem naselju. (Foto: Tomaž Pipan)

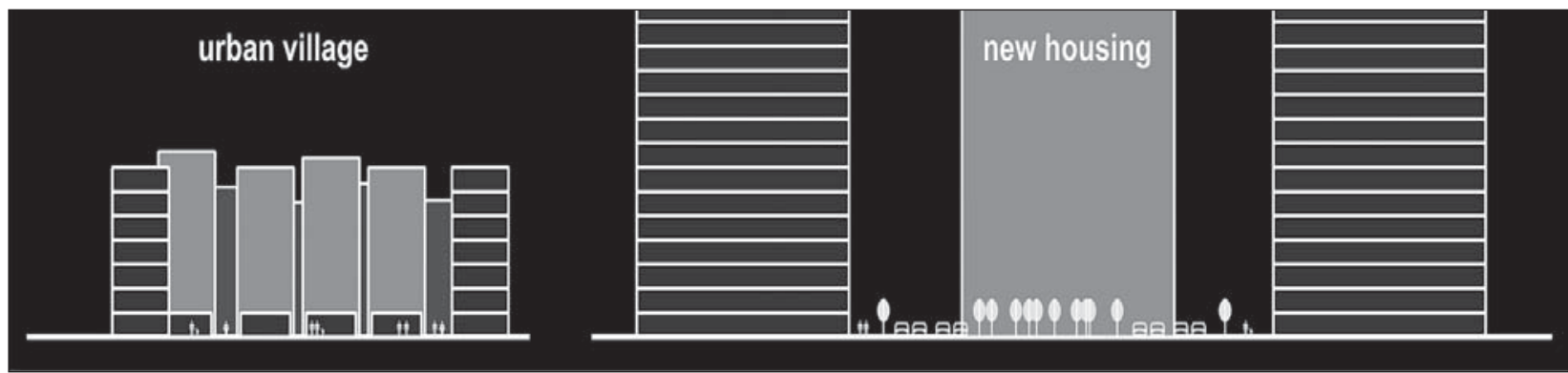

Slika 11: Obseg javnega prostora v urbani vasi in novem stanovanjskem naselju. (Foto: Tomaž Pipan) 


\section{Branje Šenzena po Rossiju}

Po orisu družbenopolitičnih razmer in pomembnejših vidikov razvoja Šenzena bomo poskusili materializacijo mesta razložiti s pomočjo Rossijeve metodologije. Njegova poglavitna domneva je, da je mogoče mesto brati in razumeti zgolj na podlagi njegove oblike, saj ima oblika sposobnost, da ohrani in zadrži zgodovino, v kateri so vtisnjeni procesi nastanka mesta in razlogi zanj.

\subsection{Avtonomija ubrane znanosti}

Rossi trdi, da je urbanizem mogoče razumeti kot samostojno vedo, ki nam nudi instrumente za branje, razumevanje in naslavljanje mesta. To je omogočeno na podlagi branja fizične oblike mesta, saj je ta oblika morfološki odtis zgodovinskih, kulturnih in družbenih procesov (Rossi te procese skupno imenuje urbana dinamika). Takšna opredelitev avtonomije je nekoliko dvomljiva, saj Rossi dovoljuje vstop tistim procesom, ki so sicer predmet raziskave drugih znanstvenih področij. Za primerjavo bi lahko dali Eisenmanovo interiornost arhitekture. Eisenman olušči arhitekturno formo vsega, še posebej pomena, in jo preučuje povsem abstraktno in kompozicijsko. S tem želi doseči nemotivacijo označevalca $v$ arhitekturnem jeziku (Eisenman, 1999). Rečemo lahko, da je to najbolj avtonomno stališče, kar jih lahko kdo zavzame. Čeprav oba, Rossi in Eisenman, govorita o nekakšni neodvisnosti znanstvenega polja, pa Eisenman razume interiornost arhitekture popolnoma drugače, kot Rossi razume avtonomijo urbanizma.

Vprašanje avtonomije ostaja odprto, še zlasti zato, ker ga Rossi nikjer jasno ne opredeli in ga ne pospremi z očitnim primerom. Naslednja dva odlomka bosta to bolje pojasnila.

"[Oblika mesta] je avtonomna le takrat, kadar jo razumemo kot temeljno danost, kot konstrukt in kot arhitekturo, le takrat, kadar analiziramo urbane artefakte takšne, kakršni so ... "(Rossi, 1984: 22).

"Arhitektura mesta povzema obliko mesta in ta oblika je izhodišče za razmišljanje o težavah mesta ..."(Prav tam: 29).

S preučevanjem oblike lahko »razmišljamo o težavah mesta«; tako lahko ugotovimo, kako mesto deluje. Z obnovo postopka nastajanja oblike (z zgodovino te oblike) lahko opišemo procese, ki so bili bistveni za njen nastanek. Rossi tako obrača vzročnost in določa vzrok s posledico, z obliko. Ugotavlja, kakšni so bili procesi in kako so delovali. To pa ne pripelje vedno do pravih procesov; vodi lahko le v množico različnih procesov, ki bi lahko imeli vlogo pri nastajanju določene urbane forme. Če hočemo videti, kateri izmed vseh možnih procesov so dejansko prispevali $\mathrm{k}$ obliki in kako, jih moramo opredeliti z njihovimi disciplinami.

Problem avtonomije urbanistične znanosti ni povezan samo s Šenzenom, ampak je širši in ostja nerazrešen. Kljub navedenemu pa za namen pričlujoče razprave recimo, da je mesto mogoče preučevati iz oblike same. Na podlagi te domneve bomo poskusili $\mathrm{Z}$ »branjem« urbane vasi in se soočili s problemom, ki ga kot zaprta urbana entiteta predstavlja za nižji družbeni razred.

S preučevanjem morfologije urbane vasi in njeno primerjavo $\mathrm{z}$ novimi stanovanjskimi naselji ugotovimo, da življenjske razmere $\mathrm{v}$ teh vaseh niso najboljše - slaba osončenost, malo odprtega - javnega prostora. To lahko pomeni, da so najemnine veliko nižje in da $\mathrm{v}$ teh vaseh živijo ljudje $\mathrm{z}$ nižjim dohodkom. S preučevanjem oblike urbane vasi pa nikakor ne moremo ugotoviti razlogov za take razmere. $\mathrm{Z}$ "regresivnim« utemeljevanjem ne moremo povsem razložiti, zakaj je to območje pozidano tako zelo drugače kot preostalo tkivo. Za razumevanje tega moramo razumeti procese $\mathrm{v}$ ozadju nastanka naselij, to, da so bili vaščani lastniki zemlje in da so se jim za razlastitev obdelovalnih površin oddolžili $\mathrm{z}$ zazidalnim dovoljenjem in $\mathrm{z}$ dovoljenjem za oddajanje zgrajenih zgradb. Vlada je pri odškodnini zamižala na eno oko in ni vztrajala pri upoštevanju gradbenih pravil. Zgolj z opazovanjem oblike in njenih fizičnih preobrazb $\mathrm{v}$ preteklosti ne moremo pojasniti vseh družbenopolitičnih dejavnikov. Preučevanje oblike $\mathrm{z}$ regresivno zgodovinsko metodo je treba dopolniti $\mathrm{z}$ razumevanjem zgodovinskih, družbenih in gospodarskih procesov in razmer.

\subsection{Trajnost in zgodovinska metoda}

Ko Rossi govori o trajnosti in vztrajnosti elementov v mestu, se sklicuje na teorijo trajnosti, kot jo je opredelil Poète. Loči dve vrsti trajnih elementov, in sicer tloris in načrt mesta na eni strani ter spomenike in primarne elemente na drugi (posvetili se jim bomo pozneje). Vztrajnost teh elementov lahko razvoj mesta spodbudi ali zavre. Rossi v duhu svoje teorije zagovarja vztrajnost oblike, ki sama po sebi lahko motivira okoliško tkivo in s tem sproži rast mesta. Trajnost je tesno povezana z zgodovinsko primerjalno metodo, s katero je mogoče vztrajnosti elementov razčleniti in razumeti njihovo vlogo $v$ mestu. Če razumemo zgodovino oblike elementa, ki se ohranja, ga lahko razumemo na podlagi tega, kako deluje in kaj povzroča. 
Kaj pa se zgodi, ko preučujemo urbano obliko Šenzena, zlasti v njegovi zgodnji fazi s 15-letno in celo krajšo "zgodovino«? To v kontekstu evropskih (in celo ameriških) mest ne moremo razumeti kot zgodovino. Pri analizi oblike Šenzena ne moremo uporabiti "zgodovinske« dedukcije, da bi ugotovili, kako se je urbana forma razvijala. Pred sedanjo urbano formo ni bilo ničesar, na podlagi česa bi se območje lahko urbaniziralo; ni bilo nikakršnih urbanih artefaktov. Razvoj Šenzena zato niso mogli sprožiti ne zgodovina artefaktov in tudi ne trajnostni elementi. Urbana vas je edini artefakt, ki bi lahko pogojno spadal v to razčlenitev. ${ }^{[2]}$ Sicer je ni mogoče opredeliti kot primarni element, a ima vsaj lastnost vztrajnosti. Vendar vztrajnost vasi ne deluje na mesto ne spodbudno niti ne zaviralno. V primerjavi z drugimi silami, ki ga oblikujejo, je torej skrajno nepomembna in je ne moremo upoštevati.

Če hočemo razložiti trajnosti in vztrajnosti, ki določajo obliko v zgodnji fazi, moramo preučiti nematerialne in ideološke dejavnike. Ena izmed trajnosti je ideološka podoba, ki jo spodbuja režim. To je razlog za velike odprte prostore in mogočne promenade. Drug tak dejavnik je velika želja po "zahodnem"načinu življenja. Ideja o trajnosti in vztrajnosti elementov je dobra, vendar ne sme biti razumljena zgolj kot sedimentna lastnost fizične oblike. Vsebovati mora tudi metafizične trajnosti, kakršne so ideologija, kultura in identiteta, ki se ohranja pri posameznikih, skupinah, državah in političnih konstruktih, če hočemo pojasniti vse spremembe v zgodovini mesta.

\subsection{Funkcija proti tipologiji}

Tipologija je za Rossija konceptualni operativni pojem. Povzema ga po Quatremèru de Quincyju. Za stvari, ki sledijo enakim osnovnim pravilom in načelom, lahko rečemo, da so enake tipologije. Za Rossija to pomeni, da je ideja tipologije ločena od fizične oblike in je vzpostavljena kot konceptualna entiteta, ki deluje kot aparat; kot instrument za analizo in merjenje. Tip lahko razumemo tudi kot instrument, ki deluje s časovno komponento, na primer z zgodovino in s kolektivnim spominom. Temu je potrebno dodati, da tradicionalno razumevanje tipa (določena oblika $\mathrm{z}$ določenim programom) Rossi razume kot model, saj je zanj tradicionalna razlaga tipologije napačna, ker upošteva samo funkcionalne vidike. Rossi namreč močno razvrednoti pomen funkcije in daje prednost abstraktnejšim pojmom, kadar se ukvarja s tipologijo.

Rossijevo idejno določitev sicer lahko sprejmemo, vendar moramo pri Šenzenu izreči majhen pomislek o negaciji funkcije, ki se nanaša na tipologijo. Najprej je tu spet očitno vprašanje časa in zgodovine, vtisnjene v Šenzen, zlasti v zgodnji fazi. Urbana vas bi morala biti iz tega izvzeta, saj ustreza opredelitvi tipologije, zato se posvetimo "novemu tkivu«. Edini zgodovinski in kolektivni spomin, ki je vtisnjen v "nove« dele mesta, je ideološki in gospodarski. Ideologija in gospodarstvo brez posebnih razlik prežemata vse plasti mesta, zato bi razumevanje tega spomina z vidika, ki izključuje funkcijo, povzročilo, da bi imeli vse dele tkiva za tipološko enake. Če v to dedukcijo ne vpeljemo funkcije, ne moremo razlikovati med deli, ki se zares razlikujejo med sabo in za katera veljajo drugačna pravila.

Ko so gradili industrijo, so imeli v mislih popolnoma drugačno funkcijo kot takrat, ko so gradili stanovanja. Industrijski objekti se zato od stanovanjskih ne razlikujejo le po fizični obliki, ampak tudi po tem, kako organizirajo prostor.

Funkcija vpelje razlikovanje oblike in ji omogoča, da se odziva na spremembe in sile $\mathrm{v}$ mestu. Funkcije ne smemo razumeti kot statične entitete, $\mathrm{v}$ kateri lahko ena funkcija deluje le $\mathrm{v}$ eni vrsti oblike (to priznava tudi Rossi), nasprotno, funkcija je dinamična lastnost, pripisana fizični obliki. Tako lahko oblika v času nakopiči več funkcij, se "raztegne« v času in postane po Rossiju primarni element ali spomenik. A medtem ko je za Rossija ta sposobnost generator, ki izvira iz same oblike, lahko rečemo, da je to mogoče le takrat, kadar ima oblika različne lastnosti, med katerimi mora biti tudi funkcija.

Rossi pozneje $\mathrm{v}$ svoji knjigi dovoljuje in priznava pomen funkcij, vendar le kot »algebro vrednosti« (prav tam: 46), in jih degradira v »nujno zlo«. Pravi:

"... če urbani artefakti pomenijo samo težavo na področju organizacije in členitve [funkcije], potem nimajo ne kontinuitete ne individualnosti. Spomeniki in arhitektura nimajo razloga za obstoj ..." (Prav tam: 48).

\subsection{Primarni elementi in spomeniki}

»[Primarni elementi] so elementi, ki so sposobni pospešiti proces urbanizacije« (prav tam: 87). So jedra združitve in zgostitve, ki delujejo kot generatorji urbanega - spreminjajo urbano tkivo in pospešujejo razvoj. So neponovljivi in edinstveni elementi $\mathrm{v}$ tkivu mesta. $\mathrm{Z}$ drugimi besedami, $\mathrm{v}$ sestavi tkiva ne bi smeli prevladovati primarni elementi, saj bi izgubili sposobnost ustvarjanja novega urbanega tkiva in ne bi bili več primarni elementi.

Posebno vlogo med primarnimi elementi imajo tisti, ki jim Rossi pravi spomeniki. So posebna vrsta primarnih elementov, ki mesto aktivirajo, obenem pa 
so predmeti posebnega kulturnega in zgodovinskega pomena. V svoji obliki povzemajo zgodovino in kolektivni spomin, poleg tega pa tudi kulturo. Zato so vztrajni in delujejo kot katalizatorji. V tem smislu so bistvo Rossijeve teorije, saj njihova fizična vztrajnost deluje kot zbiratelj zgodovine ter sociologije mesta in procesov v njem. Njihova oblika se zavzema za misli o njih samih in misli o nekdanjem jazu.

Če se vrnemo k razvpiti Šenzenovi zgodnji fazi (iz katere je izvzeta urbana vas, za katero smo že ugotovili, da ni primarni element), lahko oblikujemo naslednjo trditev. Šenzen je 15 let star artefakt in kot tak nima posebne zgodovine, zato se v njegove dele ni mogel vtisniti kolektivni spomin. Torej ne moremo nobenemu delu reči spomenik. Nadalje, ker je bil Šenzen industrijsko mesto in torej v veliki večini sestavljen iz stanovanjskih in industrijskih delov, ni bilo edinstvenih in različnih elementov, ki bi lahko sprožili urbanizacijo. Torej ni bilo nobenih primarnih elementov.

Če združimo obe domnevi, dobimo urbano obliko, ki se zaradi očitne odsotnosti zgodovine, primarnih elementov in spomenikov ne ujema z Rossijevo mislijo o mestu in je ne moremo tako razumeti. To odpira dve zelo pomembni vprašanji. Prvič, kaj če ta urbana oblika ni mesto, ampak le velikanska vas s štirimi milijoni prebivalcev? In drugič, kaj pojasnjuje preskok iz teh razmer v nove, iz zgodnje faze v poznejšo?

Na drugo vprašanje bi lahko odgovorili tako: če ni bilo ničesar fizičnega in, kar je še pomembneje, če ni bilo zgodovine, ki bi utemeljila nastanek primarnih elementov, potem so morale delovati nesnovne sile, sile, ki ne izvirajo iz fizične oblike a so kljub temu sposobne ustvarjati. Povzeli bi lahko, da so nesnovne sile zgoščene v politikah in ideologijah, ki zmorejo ustvariti urbano obliko in primarne elemente.

Prvo vprašanje, tj. kakšno vrsto grajenih oblik lahko imenujemo mesto, pa je širši problem, ki ni povezan zgolj z nesposobnostjo Rossijevega utemeljevanja. Moramo se strinjati $z$ njegovo tezo, da je fizično obliko, ki nosi samo funkcijo, in če je ta funkcija tako prevladujoča in enolična, kot je v zgodnji fazi Šenzena, težko razumeti kot mesto.

Kaj pa, če nezmožnost tega, da bi to tvorbo imenovali mesto, ni povezano s tvorbo samo, ampak z utemeljevanjem le-te? Zahodna misel razume kapitalistično mesto $\mathrm{v}$ skladu $\mathrm{z}$ nekaterimi orisi utemeljevanja, ki so v zahodnem kulturnem okviru globoko zakoreninjeni. Kaj se zgodi, ko pojem kapitalističnega mesta prenesemo na Kitajsko, ki je več tisoč let živela $\mathrm{v}$ zgodovinski in kulturni osami in je zato ubrala popolnoma drugačno pot kot zahodni svet? Kdo lahko reče, da Šenzen v svoji zgodnji fazi ni bil mesto, prav toliko kot je mesto danes?

\section{Sklep}

Razumevanje mesta kot grajene entitete zgolj po njegovi obliki je pohvalno, vendar ne more utemeljiti in pojasniti vseh procesov, ki se dogajajo v sodobnih mestih, kakršno je Šenzen. Teorija, ki se v evropskih in ameriških mestih lepo ujema z zgodovino, lahko začne razlagati na novo razvijajoča se somestja le po določenem času. Rossijeva teorija ne pojasnjuje preskokov, ki so se zgodili med preobrazbo nemotivirane velike vasi v mesto. Uporabljeni zgodovinski primerjalni metodi manjka ključna sestavina, zgodovina.

Rossijeva teorija na splošno deluje dobro, vendar bi predlagali nekaj sprememb. Težko si predstavljamo, da urbana znanost lahko deluje kot samostojno področje. Dopolnjevati jo je treba $z$ drugimi področji. Misel o vztrajnosti, ki potrjuje samo sedimentni potencial fizične oblike, je treba okrepiti z metafizičnimi trajnostmi, na primer $z$ ideologijami. Bolj bi morali poudarjati pomen funkcije v tipologiji, čeprav moramo tipologijo še vedno razumeti kot konceptualni pojem z zgodovinsko komponento. Zamisel o primarnih elementih in spomenikih je smiselna, čeprav lahko rečemo, da razumevanje le-te zgolj na osnovi oblike ne moremo razložiti sodobnih urbanih pojavov, kakršen je Šenzen. To misel lahko dopolnimo z idejo, ki dovoljuje, da tudi nesnovne koncepte razumemo kot primarne elemente - enako kot so razumljeni deli mesta.

\footnotetext{
Tomaž Pipan, univ. dipl. inž. arh.

Architectural Association (AA) School of Architecture, London
} E-pošta: tomaz@elastik.net

\section{Opombe \\ [1] Izraz »urbani artefakt« je uporabljen v smislu, v kakršnem ga je Aldo Rossi opredelil $\vee$ The Architecture of the City. \\ [2] Drugi izjemno »vztrajni« element je tloris cest, ki zelo vpliva na obliko mesta. A ker Rossi zavrača popolnoma funkcionalni pristop kot imper- ativno lastnost artefakta, ta dejavnik ne velja za najpomembnejšega. Zato je izvzet iz raziskave.}

\section{Viri in literatura}

Chung C. J., Inaba, J., Koolhaas, R., Leong, S. T. (ur.) (2001) A Great Leap Forward. Köln, Taschen.

Eisenman, P. (1999) Diagram Diaries. New York, Universe Publishing.

Internet 1: Google Earth (sneto 6. 5. 2008).

Internet 2: http://www.panoramio.com/photo/3392923 (sneto 28. 1. 2008).

Rossi, A. (1984) Architecture of the City. Massachusetts, The MIT Press.

Uehara, Y. in dr. (2005) Casting Village Within City, Research Studio »Unknown Urbanity in China - Village within the City«. Rotterdam, Berlage Institute. 